\section{References}

1. David TE, Feindel CM. An aortic valve-sparing operation for patients with aortic incompetence and aneurysm of the ascending aorta. $J$ Thorac Cardiovasc Surg. 1992;103:617-21.

2. Leyh RG, Schmidtke C, Sievers HH, Yacoub MH. Opening and closing characteristics of the aortic valve after different types of valve-preserving surgery. Circulation. 1999;100:2153-60.

3. De Paulis R, De Matteis GM, Nardi P, Scaffa R, Bassano C, Chiariello L. Analysis of valve motion after the reimplantation type of valve- sparing procedure (David 1) with a new aortic root conduit. Ann Thorac Surg. 2002;74:53-7.

4. Demers P, Miller DC. Simple modification of "T. David-V" valvesparing aortic root replacement to create graft pseudosinuses. Ann Thorac Surg. 2004;78:1476-81.

5. Cochran RP, Kunzelman KS, Eddy AC, Hofer BO, Verrier ED. Modified conduit preparation creates a pseudosinus in an aortic valvesparing procedure for aneurysm of the descending aorta. $J$ Thorac Cardiovasc Surg. 1995;109:1049-58.

\title{
An entirely endovascular approach to the repair of an ascending aortic pseudoaneurysm
}

\author{
Firas F. Mussa, MD, ${ }^{a, b}$ Scott A. LeMaire, MD, ${ }^{a, c}$ John Bozinovski, MD, ${ }^{a, c}$ and Joseph S. Coselli, MD, ${ }^{a, c}$ Houston, Tex
}

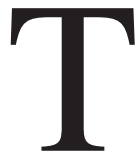

raditional surgical repair of an ascending aortic pseudoaneurysm requires resternotomy, cardiopulmonary bypass, and often hypothermic circulatory arrest. These procedures are complex, technically challenging, and associated with significant mortality. ${ }^{1}$ The rapidly advancing technology of catheter-based interventions has rarely addressed diseases of the ascending aorta, because the proximity to the coronary and brachiocephalic arteries makes such interventions particularly challenging. ${ }^{2-4}$ Here we describe the use of a stent-graft to perform an entirely endovascular repair of a symptomatic ascending aortic pseudoaneurysm in a patient who was a poor candidate for open surgical intervention.

\section{Clinical Summary}

Review of patient data for this report was approved by the institutional review board at Baylor College of Medicine. Informed consent for the report was obtained from the patient. An 82-yearold woman had undergone emergency repair of an acute iatrogenic dissection localized to the ascending aorta 18 months previously. In her previous operation, primary aortic repair with obliteration of the false lumen and resuspension of the aortic valve had been accomplished by means of surgical adhesive, aortic plication with felt strips, and direct closure of the aortotomy. Concomitantly, the patient had undergone bypass of the left anterior descending coronary artery with the left internal thoracic artery. She subsequently

From the Cardiovascular Surgery Service of the Texas Heart Institute at St. Luke's Episcopal Hospital, ${ }^{\mathrm{a}}$ and the Divisions of Vascular Surgery and Endovascular Therapy ${ }^{\mathrm{b}}$ and Cardiothoracic Surgery, ${ }^{\mathrm{c}}$ Michael E. DeBakey Department of Surgery, Baylor College of Medicine, Houston, Tex.

Received for publication Sept 26, 2006; accepted for publication Oct 9, 2006.

Address for reprints: Scott A. LeMaire, One Baylor Plaza, BCM 390, Houston, TX 77030 (E-mail: slemaire@bcm.edu).

J Thorac Cardiovasc Surg 2007;133:562-3

$0022-5223 / \$ 32.00$

Copyright $\odot 2007$ by The American Association for Thoracic Surgery doi:10.1016/j.jtcvs.2006.10.010 required placement of an automatic defibrillator-pacemaker and treatment for chronic congestive heart failure.

The patient was referred to our center after an evaluation for chest pain revealed an expanding ascending aortic pseudoaneurysm. Because of her poor physical condition and previous sternotomy, open repair was considered to be an extremely high-risk option. Treatment with an endovascular stent-graft as a novel alternative was discussed with the patient and her family.

A retroperitoneal incision was used to access the left external iliac artery. A 7F sheath was introduced into the right brachial artery. A pigtail marker catheter was used to measure the distance between the right coronary and innominate arteries (Figure 1, A). A guidewire was advanced to the ascending aorta from the left external iliac artery and exchanged for an extra-stiff Lunderquist wire (Cook Medical Inc, Bloomington, Ind). A 24F guiding sheath was inserted over the stiff wire. After angiographic confirmation, a $40 \times 100$-mm GORE TAG thoracic endograft (W. L. Gore \& Associates, Inc, Flagstaff, Ariz) was deployed through the left external iliac artery. Completion angiography confirmed total exclusion of the pseudoaneurysm, with brisk antegrade flow into the right coronary and innominate arteries (Figure 1, $B$ ).

The patient's initial recovery was complicated by her deconditioned state; she did not have any neurologic deficits but required extensive physical therapy because of her generalized weakness. On postoperative day 15 , she had an acute brainstem stroke and died. Autopsy confirmed that the stent-graft had not migrated and that the coronary ostia and brachiocephalic arteries were patent.

\section{Discussion}

Pseudoaneurysm is an increasingly recognized complication of ascending aortic replacement; a magnetic resonance imaging study found an incidence of $13 \% .^{5}$ These pseudoaneurysms have a poor prognosis because of the risks involved in complex reoperations in patients with multiple comorbidities. Endovascular approaches may provide a unique treatment opportunity for patients who have ascending aortic pseudoaneurysms but are not candidates for conventional open repair.

To be considered for treatment with an endovascular stentgraft, patients must have adequate landing zones to ensure proper 

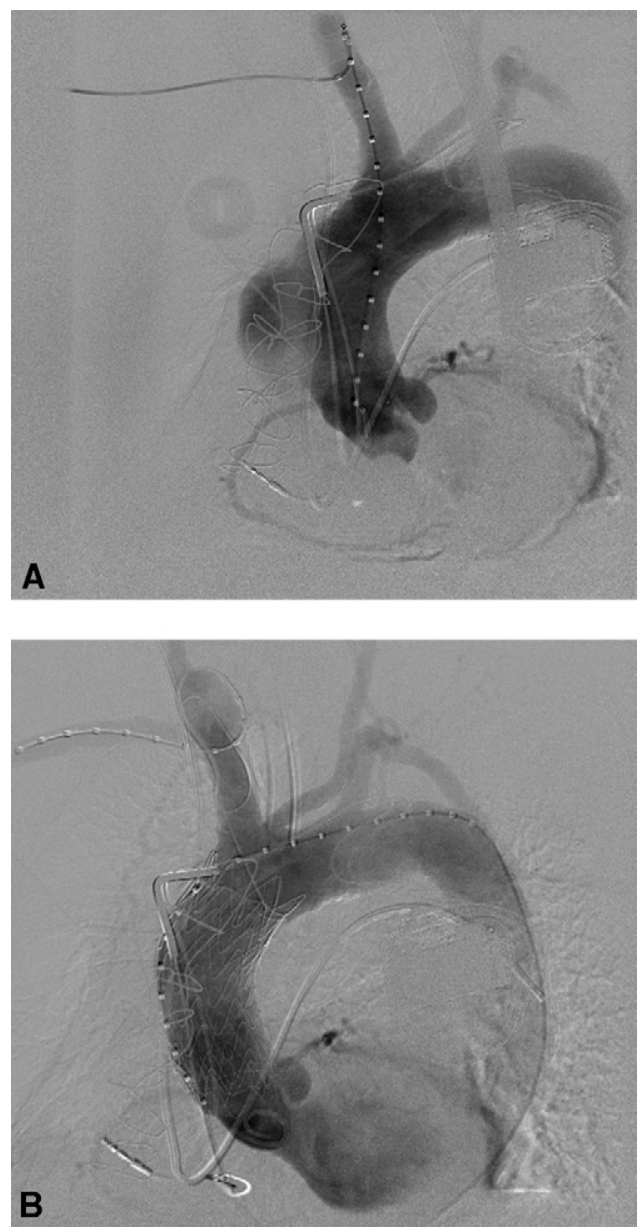

Figure 1. Intraoperative aortography showing pseudoaneurysm arising from mid-ascending aorta (A) and complete exclusion of pseudoaneurysm after stent-graft deployment, with antegrade flow in brachiocephalic branches and both coronary arteries and transient valvular insufficiency caused by position of pigtail catheter (B).

circumferential seals and complete aneurysmal exclusion. Patients with ascending aortic disease often have inadequate landing zones and a substantial risk of flow obstruction of the coronary and brachiocephalic arteries, so endovascular stent-grafts are not usually considered for these patients. To compensate for inadequate landing zones, hybrid approaches combining open surgical debranching of the supra-aortic trunks with endovascular stent-graft placement have been used successfully in high-risk cases. Alternative endovascular approaches to ascending aortic pseudoaneurysms have included temporary occlusion with a balloon catheter (before surgical repair) ${ }^{2}$ and thrombosis through transcatheter intra-arterial thrombin injection. ${ }^{3}$ Komanapalli and colleagues ${ }^{4}$ successfully used an Amplatzer septal occluder device (AGA Medical Corporation, Golden Valley, Minn) to exclude an ascending aortic pseudoaneurysm in a poor surgical candidate.

In our patient, we were able to position the stent-graft by using the natural curve of the ascending aorta and successfully exclude the pseudoaneurysm without covering the coronary or innominate arteries. Although this necessitated positioning the floppy end of the extra-stiff guidewire against the aortic valve, the resulting intermittent aortic valvular insufficiency did not produce untoward hemodynamic effects. Regrettably, the patient did not recover from the aortic repair, even though a minimally invasive approach was used. Despite this unfortunate outcome, this report describes a novel approach to managing focal ascending aortic disease in high-risk patients and expands the potential indications for thoracic endografting.

We thank Stephen N. Palmer, PhD, ELS, for providing editorial assistance.

\section{References}

1. Sullivan KL, Steiner RM, Smullens SN, Griska L, Meister SG. Pseudoaneurysm of the ascending aorta following cardiac surgery. Chest. 1988;93:138-43.

2. Mesana TG, Caus T, Gaubert J, Collart F, Ayari R, Bartoli J, et al. Late complications after prosthetic replacement of the ascending aorta: what did we learn from routine magnetic resonance imaging follow-up? Eur J Cardiothorac Surg. 2000;18:313-20.

3. Lin PH, Bush RL, Tong FC, Chaikof E, Martin LG, Lumsden AB. Intra-arterial thrombin injection of an ascending aortic pseudoaneurysm complicated by transient ischemic attack and rescued with systemic abciximab. J Vasc Surg. 2001;34:939-42.

4. Komanapalli CB, Burch G, Tripathy U, Slater MS, Song HK. Percutaneous repair of an ascending aortic pseudoaneurysm with a septal occluder device. J Thorac Cardiovasc Surg. 2005;130:603-4.

5. Hatfield DR, Fried AM, Ellis GT, Mattingly WT Jr, Todd EP. Intraoperative control of an ascending aortic pseudoaneurysm by Fogarty balloon catheter: a combined radiologic and surgical approach. Radiology. 1980; 135:515-7. 